\title{
The Impact of Using Cambly on EFL University Students' Speaking Proficiency
}

\author{
Maram S. Alshammary ${ }^{1}$ \\ ${ }^{1}$ College of Languages and Translation, Al-Imam Mohammed Bin Saud Islamic University, Riyadh, Saudi \\ Arabia \\ Correspondence: Maram S. Alshammary, College of Languages and Translation, Al-Imam Mohammed Bin Saud \\ Islamic University, Riyadh, Saudi Arabia.
}

Received: June 1, 2020

doi: 10.5539/elt.v13n8p12
Accepted: July 1, 2020

Online Published: July 2, 2020

URL: https://doi.org/10.5539/elt.v13n8p12

\begin{abstract}
This study sought to investigate the impact of using Cambly, a computer-mediated communication tool, on the speaking proficiency of English as a foreign language (EFL) learners. Further, it aimed to explore the participants' perceptions of using Cambly. The study employed an experimental design featuring a mixed-methods approach to data collection that involved pre- and post-testing of the participants' speaking proficiency as well as semi-structured face-to-face interviews. The study sample consisted of 28 EFL university students who were divided into the control and experimental groups. The participants in the experimental group used Cambly to conduct audio calls with native speakers of English over a period of 4 weeks. The quantitative analysis of the participants' speaking proficiency tests revealed no significant differences between the experimental and control groups' post-test scores. Moreover, no significant differences were found between the experimental group's pre- and post-test scores. The qualitative analysis of the participants' interviews revealed that the use of Cambly had a positive influence on their speaking proficiency, motivation, anxiety level, speaking opportunities, autonomy, social relationships, and cultural awareness.
\end{abstract}

Keywords: Cambly, CMC, educational technology, EFL learners, online communication, speaking proficiency

\section{Background}

Reaching a satisfactory level in relation to the speaking component of second language (L2) learning is difficult, especially in a foreign context. In such a context, students' lack of exposure to authentic language in a natural environment can lead to deficiencies in terms of their L2 speaking proficiency (Alharbi, 2015; Nowrozi, 2011; Yen, Hou, \& Chang, 2015). Even L2 teachers' attempts to expose their students to authentic language during classroom activities might not be sufficient to ensure satisfactory progress in this regard (Nowrozi, 2011). Because speaking is a skill that cannot be mastered simply through learning the grammatical rules of the language in question (Bygate, 2010), some researchers have sought to study the effectiveness of integrating computer-mediated communication (CMC) tools into classroom activities.

CMC tools were first used in the linguistics field in the 1980s (Warschauer, 1996), with the associated process being defined by Herrings (1996) as "communication that takes place between human beings via the instrumentality of computers" (p. 1). Based on that definition, CMC can be said to include any kind of communication, whether written, oral, or visual, that takes place between individuals using technology. Beatty (2010) extended the accepted definition by suggesting that the goal of L2 communication when using CMC tools is not always learning and teaching, although improvements in the learner's L2 proficiency might occur. Additionally, Beatty (2010) described two main types of CMC: synchronous and asynchronous CMC. In the case of synchronous $\mathrm{CMC}$ tools, the communication occurs simultaneously, while the communication does not have to be simultaneous with asynchronous CMC tools. The prior studies that have investigated the effectiveness of different CMC tools in terms of improving users' L2 speaking skills can be divided into two categories based on the type of CMC tool used: studies that used synchronous CMC tools and studies that used asynchronous CMC tools.

Based on the above, the present study sought to extend the prior literature concerning the evaluation of synchronous CMC tools in relation to English as a foreign language (EFL) university students' speaking 
proficiency by using Cambly as the CMC platform of interest. In addition, the study sought to explore the participants' attitudes toward using Cambly when learning and practicing their EFL speaking.

\subsection{Research Hypotheses}

In terms of the quantitative aspect of this study, two hypotheses were tested:

1. There will be a statistically significant difference between the mean post-test scores of the experimental and control groups.

2. There will be a statistically significant difference between the mean pre- and post-tests scores of the experimental group.

\subsection{Research Questions}

With regard to the qualitative aspect of this study, two research questions were addressed:

1. What impact does the use of Cambly have on female Saudi EFL students' speaking proficiency?

2. What are the students' attitudes toward the use of Cambly when learning and practicing EFL speaking?

\section{Literature Review}

\subsection{The Role of Social Communication in Language Learning}

A number of theories emphasize the importance of social communication in relation to the process of language learning. For instance, the communicative competence theory introduced by Hymes (1972) suggests that learning a language is not limited to simply learning the grammatical structure and semantics of that language. Rather, language is governed by what Hymes refers to as "the rules of speech acts" (p. 60), which can be learned and developed through social communication. These rules explain which context suits a particular utterance. Based on this, if L2 learners depend solely on classroom activities that focus on grammar and semantics, their ignorance of the rules of speech acts might lead them to produce well-formed utterances that are nevertheless inappropriate in a given context.

Another theory that emphasizes the importance of social communication is Vygotsky's (1978) sociocultural theory. According to Vygotsky (1978), learners come to learn and develop a language through the assistance of other individuals who are more skillful with that language than they are. Vygotsky referred to an area known as the "zone of proximal development" (p. 85), which is located between the area that includes the learner's abilities and the area that includes the learner's deficiencies. Thus, any task the learner performs with the assistance of other individuals in the zone of proximal development is transmitted from his/her area of deficiencies to his/her area of abilities.

In his input theory, Krashen (1982) argued that the teaching of speaking cannot be performed in a direct way. Instead, exposing language students to an input that is slightly more advanced than their own level of proficiency will eventually lead to noticeable improvements in their L2 speaking proficiency. The input theory has now been extended through negotiations by other researchers. For instance, the interaction theory proposed by Long (1983) added the notion that an input is only beneficial if it leads to meaning negotiation among speakers. Moreover, in introducing the output theory, Swain (1985) assumed that the output is more important than the input in the context of language learning.

In light of the above-mentioned theories, CMC should be considered an influential tool in terms of the language learning process. Through the use of Cambly, the participants in the present study can practice their language skills in authentic contexts and therefore improve their communicative competence. Additionally, the participants can both collaborate on tasks and practice speaking with more skilled language learners, which should lead to their engaging in more successful learning, as suggested by Vygotsky (1978). Cambly, an online platform based on informal chatting, should provide the participants with opportunities to receive and produce comprehensible inputs and to engage in the negotiation of meaning.

\subsection{The Impact of CMC Tools on L2 Speaking Proficiency}

A number of studies have sought to evaluate the impact of asynchronous CMC tools on L2 learners' speaking proficiency. Different tools have been investigated in this regard, including voicemail (Wang \& Chang, 2011), voice blogging (Sun, 2012), video blogging (Alonayzan, 2015; Hung \& Huang, 2015), PowerPoint (Buckingham \& Alpaslan, 2017), and social media platforms such as LINE (Wu, Hsieh, \& Yang, 2017) and Facebook (Lin \& Hwang, 2018). Further, a study by Yen et al. (2015) blended the use of an asynchronous tool (Facebook) with a synchronous tool (Skype). All these studies revealed that the use of CMC tools can prompt L2 students to 
noticeably improve their speaking proficiency, except for the study by Sun (2012), which revealed that voice blogging had no impact on the participants' L2 speaking proficiency.

Similarly, studies have been conducted to investigate the effectiveness of synchronous CMC tools in relation to L2 learners' speaking proficiency. Among the synchronous CMC tools that have been examined with regard to their efficacy are games (Alfulaih, 2017; Grimshaw \& Cardoso, 2018; Liu \& Chu, 2010), MSN messenger and Audacity (Ko, 2012), written chats using ICQ (Mehr, Zoghi, \& Assadi, 2013), Skype (Castañeda, 2019; Wu, Marek, \& Chen, 2013; Yeh \& Lai, 2019), VoiceThread (Castañeda, 2019; Dugartsyrenova \& Sardegna, 2017), and FaceTime (Castañeda, 2019).

Castañeda (2019) tested the impact of CMC tools on participants' speaking skills using an experimental design that divided 53 Spanish as a foreign language (SFL) students into two groups based on their proficiency levels: intermediate 1 and intermediate 2. The experiment was conducted in three stages. During the first stage, the participants were exposed to a language input. They then reflected on that input during the second stage. Finally, during the third stage, the participants engaged in both online and face-to-face interactions regarding the input they had received. Using the pre- and post-test method of analysis, Castañeda (2019) revealed that only one group, intermediate 2, showed improvements in their speaking proficiency by the end of the experiment. However, although Castañeda's study (2019) was similar to the present study in terms of its design and goal, it lacked a control group, which will be included in this study.

Yeh and Lai (2019) tested the impact of online lessons delivered by native speakers of English. A total of 25 Taiwanese students participated in the lessons over a period of 8 weeks. The pre- and post-test results revealed that the use of CMC tools improved the students' speaking proficiency. However, the participants in Yeh and Lai's study (2019) did not have a choice with regard to the topics selected for discussion during the online lessons. The present study adopted a different approach; the participants had full control over the topics they discussed with their Cambly tutors.

It is important to note that the results of previous studies concerning the impact of synchronous CMC tools on L2 students' speaking proficiency have not been consistent. For instance, while some researchers have found CMC tools to be beneficial in terms of learning L2 speaking (Alfulaih, 2017; Dugartsyrenova \& Sardegna, 2017; Liu \& Chu, 2010; Mehr et al., 2013: Wu et al., 2013; Yeh \& Lai, 2019), others have found CMC tools to have little or no impact (Castañeda, 2019; Grimshaw \& Cardoso, 2018; Ko, 2012). Thus, the aim of the present study was to support and elaborate on the results of prior studies by investigating the impact of Cambly, which has received only scant research interest to date, on EFL university students' speaking proficiency.

\subsection{Other Benefits of CMC Tools}

The use of CMC tools in the process of language learning offers a number of advantages. For instance, many researchers have argued that the use of CMC tools increases motivation among language learners (Alfulaih, 2017; Alghammas, 2020; Hung \& Huang, 2015; Lin \& Hwang, 2018; Liu \& Chu, 2010; Wu et al., 2017). Moreover, people generally exhibit a positive attitude toward the use of new techniques in addition to traditional classroom practices. This could explain why the use of CMC tools increases learners' motivation. Another advantage is that CMC tools provide learners with opportunities to practice their language skills in authentic situations (Alghammas, 2020; Wu et al., 2017), which helps enhance their language acquisition.

The repeated practicing of English speaking in a nonthreatening environment (Wu et al., 2017) can also help to decrease students' anxiety level (Alfulaih, 2017; Grimshaw \& Cardoso, 2018; Sun, 2012). As the students' motivation is increased and their anxiety level is decreased, the use of CMC tools can prompt them to become more autonomous and to engage in self-correction (Dugartsyrenova \& Sardegna, 2017; Guarda, 2012; Hung \& Huang, 2015; Wu et al., 2017) and meaning negotiation (Yeh \& Lai, 2019), thereby helping improve their self-confidence (Dugartsyrenova \& Sardegna, 2017).

The process behind CMC tools is usually based on chatting in pairs or with language experts, which serves to make the learning experience more enjoyable (Liu \& Chu, 2010; Wang \& Chang, 2011). An enjoyable experience is likely to facilitate language learning (Alghammas, 2020; Hung \& Huang, 2015). Furthermore, social interactions with people from different parts of the world help students build social relationships (Grimshaw \& Cardoso, 2018) and increase their cultural awareness (Wang \& Chang, 2011; Wu et al., 2013).

\section{Methods}

The present study employed an experimental design featuring a mixed-methods approach to data collection. Creswell (2014) suggested that experimental designs facilitate the investigation of the influence of using a certain treatment on the obtained results by manipulating all the other factors that could potentially interfere with 
those results. An experimental design was chosen for this study because it is the most suitable design for investigating cause-and-effect relations (Dornyei, 2007).

\subsection{Participants}

The study sample consisted of 28 female EFL students who attended a public university in Riyadh, the capital of Saudi Arabia. The participants shared similar cultural and educational backgrounds. They were all Saudi, aged between 22 and 23 years, and had studied English for 7 years at school and then for 5 years at university. Due to Saudi cultural norms, male and female students study on separate campuses. Further, female researchers cannot conduct research on male campuses (and vice versa). Therefore, the sample did not include any male participants.

\subsubsection{Sampling Procedures}

The researcher selected the study sample by emailing all the female professors in the Department of English Language and Literature to identify a class in which the experiment could be conducted. After obtaining approval from the university and from one of the contacted professors, the researcher met the seventh-level students in their classroom and explained the experiment to them. In terms of ethical considerations, the researcher invited the students to voluntarily participate in the experiment and asked their permission to record their oral tests and interviews. The researcher stressed that the gathered data would only be analyzed for research purposes.

A stratified sampling approach was then applied to divide the participants into three proficiency levels based on their pre-test scores. Students who scored between 5 and 9 were classified as low-proficiency learners, students who scored between 10 and 18 were classified as intermediate-proficiency learners, and students who scored between 19 and 25 were classified as high-proficiency learners. However, no participants were classified as being low-proficiency learners. The participants were classified into three proficiency levels to ensure that each group, whether control or experimental, would include an equal number of students with different proficiency levels and that the two groups would be similar.

After the proficiency classifications had been completed, the researcher applied a simple random distribution approach to allocate the students into two groups, namely the control and experimental groups. There were 10 intermediate-proficiency level students in the control group and 11 in the experimental group. Additionally, there were three high-proficiency level students in the control group and four in the experimental group. Overall, there were 13 students in the control group and 15 students in the experimental group.

\subsection{Data Collection Instruments}

Two different tools were used to collect data in this study. The researcher used a pre- and post-test of speaking proficiency to gauge the participants' L2 proficiency levels before and after the experiment so as to determine the impact of Cambly. In addition to the speaking proficiency test, the researcher conducted semi-structured face-to-face interviews to explore the participants' attitudes and perceptions concerning the experiment. The results of the test were analyzed quantitatively, while the participants' interview responses were analyzed qualitatively.

The two-part speaking proficiency test was adopted from Alfulaih (2017; see Appendix A). The first part contained seven questions, each of which covered a particular theme. Each participant had to choose one question and then answer it orally for 1 minute following a minute of preparation. The second part contained six pictures of famous characters; each participant had to choose one and then describe it orally for 1 minute following a minute of preparation. The researcher swapped some of the pictures from the original test with pictures of characters who are famous in the Saudi or Arab context to ensure they were known to the participants. Each participant took about 4 minutes to complete the speaking test.

The researcher chose the speaking test for two reasons. First, the participants had to use their speaking skills to answer the questions, which ensured the reliable assessment of their speaking proficiency. Second, the test included options, which meant that if a participant was not interested in a particular question, she could choose another one. This was to ensure that the participants' lack of knowledge or experience regarding a particular question would not affect the assessment of their speaking proficiency. The pre- and post-tests followed the same format, although the themes and pictures were changed to avoid a potential internal validity threat because it was important that the participants could not rely on their knowledge of the pre-test when responding to the post-test items.

The researcher adopted a rubric from the study by Harris (1969, as cited in Alfulaih, 2017) to assess the participants' pre- and post-tests (see Appendix B). They were assessed in terms of five criteria, namely grammar, 
fluency, vocabulary, pronunciation, and comprehension. For each criterion, each participant was awarded a total of five marks, which meant that the maximum total score for the whole test was 25 . The researcher used Cambly to contact a native speaker of English who has a post-graduate certificate in education, an EFL teaching certificate, and considerable experience working as an International English Language Testing System (IELTS) specialist. He was chosen as the evaluator because he is fully aware of his own language and has worked as an evaluator for about 12 years. An independent evaluator was used to prevent any interference on the part of the researcher.

The interviews consisted of eight questions designed to elicit the participants' perceptions of the experiment (see Appendix C). The rationale behind using the interview technique to collect qualitative data was that an interview approach is "most suitable for questions that require probing to obtain adequate information" (Walliman, 2011, $p$. 99). Additionally, the qualitative data were used in this study to obtain a deeper understanding of the results (Dornyei, 2007). The interviews were all conducted in Arabic (i.e., the participants' mother tongue) to enable the participants to freely express their opinions without being hampered by any language issues.

\subsubsection{Psychometric Properties of the Utilized Instrument}

In terms of assessing the validity and reliability of data collection instruments, Creswell (2014) claimed that in relation to adopted instruments, there is no need to remeasure either the validity or the reliability. In this case, making reference to the previously established validity and reliability of the utilized instrument is sufficient. In terms of its validity, Alfulaih (2017) gave the test to a panel of experts to investigate whether it measures what it is intended to measure. Further, Alfulaih (2017) used the test-retest technique to measure the reliability of the test, with a 4-week period being left between the two tests. The average scores for the two tests were found to be the same. Additionally, Pearson's correlation coefficient was used by Alfulaih (2017) to explore the relationship between the scores for the two tests. The range was found to be 0.91 , which proved it to be a reliable test.

\subsection{Cambly}

Alghammas (2020) stated that Cambly is a "commercial company founded in 2013, focusing on assisting English language learners to practice speaking skills with qualified native (or native like) tutors" (p. 23). Most Cambly tutors have teaching certificates and/or teaching experience. When users open Cambly, they can check the personal profiles of the available native speakers prior to starting the audio call so as to select the person with whom they share the most common interests and feel most comfortable with engaging in conversation.

\subsection{Study Procedures}

The present study was conducted in three phases. The first phase focused on selecting the participants and determining the most appropriate test for them. The actual experiment began during the second phase. Finally, the third phase was devoted to concluding the experiment through the completion of the post-tests and interviews.

\subsubsection{The First Phase}

During the first phase, the researcher obtained permission to conduct the experiment and identified/enrolled the participants. All participants then took the pre-test in speaking proficiency on the university campus. The test was conducted over a period of 2 days. After that, the researcher sent the participants' recorded oral tests to the evaluator for assessment. Once the evaluation was complete, the participants were divided into the control and experimental groups based on their pre-test scores. Figure 1 shows an example of the assessment tables that the evaluator created and used during the evaluation. 


\section{Speaking Assessment}

\begin{tabular}{|l|c|}
\hline Candidate Number & 7 \\
\hline Candidate Name & \\
\hline Date of Assessment & $03 / 04 / 2019$ \\
\hline Examiner Name & A. Rubbo \\
\hline
\end{tabular}
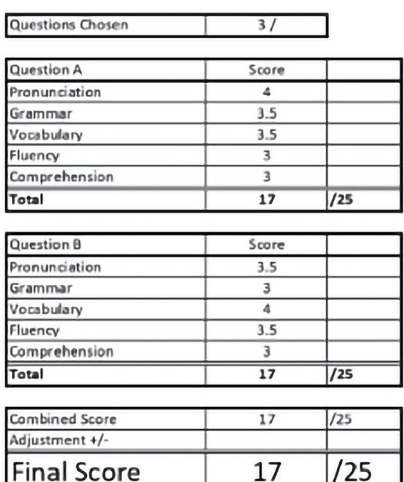

\begin{tabular}{|l|l|l|}
\hline Final Score & 17 & $/ 25$ \\
\hline
\end{tabular}

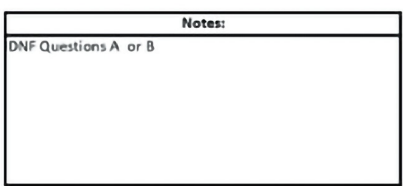

Confidential
SPEAKING EXAM ASSESSMENTS

$$
\text { (Post Test) }
$$

Speaking Assessment

\begin{tabular}{|l|c|}
\hline Candidate Number & 8 \\
\hline Candidate Name & \\
\hline Date of Assessment & $03 / 04 / 2019$ \\
\hline Examiner Name & A. Rubbo \\
\hline
\end{tabular}

\begin{tabular}{|l|l|}
\hline Questions Chosen & 3/Shakespeare \\
\hline
\end{tabular}
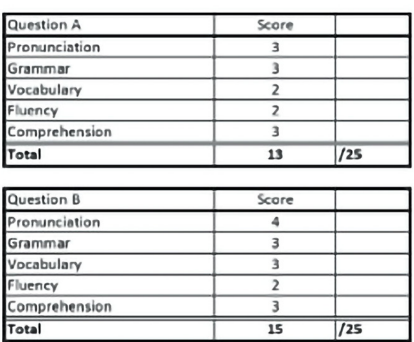

Total
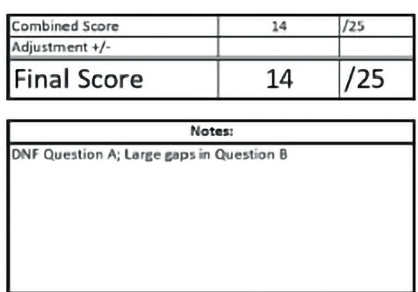

$04 / 04 / 2019$

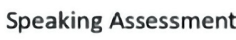

\begin{tabular}{|l|c|}
\hline Candidate Number & 9 \\
\hline Candidate Name & \\
\hline Date of Assessment & $03 / 04 / 2019$ \\
\hline Examiner Name & A. Rubbo \\
\hline
\end{tabular}
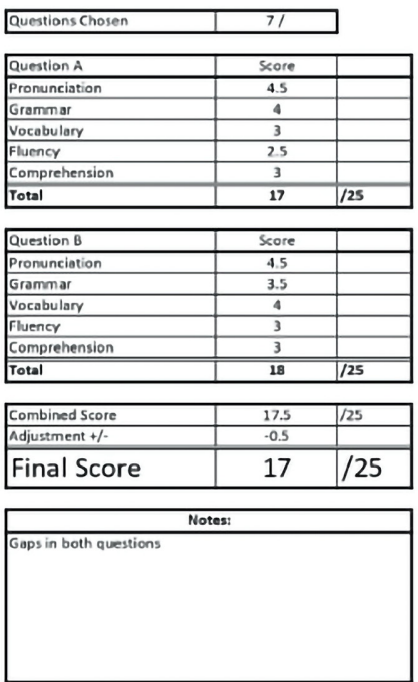

Page 3

Figure 1. Sample of the Evaluator's Assessment Table

The participants in the experimental group were invited to join a WhatsApp group created by the researcher so they could learn how to create a Cambly account and engage in audio calls with Cambly tutors. Additionally, the researcher took out a monthly Cambly subscription plan (3 days per week/15 minutes per day) for each participant in the experimental group. The total cost for each participant was approximately $\$ 50$ US.

\subsubsection{The Second Phase}

In second phase of the study, which was carried out over a period of 4 weeks, the participants in the experimental group engaged in audio calls with Cambly tutors. The researcher was available to provide encouragement and to answer any questions they might have about the tool. Figure 2 shows a screenshot taken by one of the participants during an online audio call with a Cambly tutors. The tutor's permission was obtained before the photo was taken. 


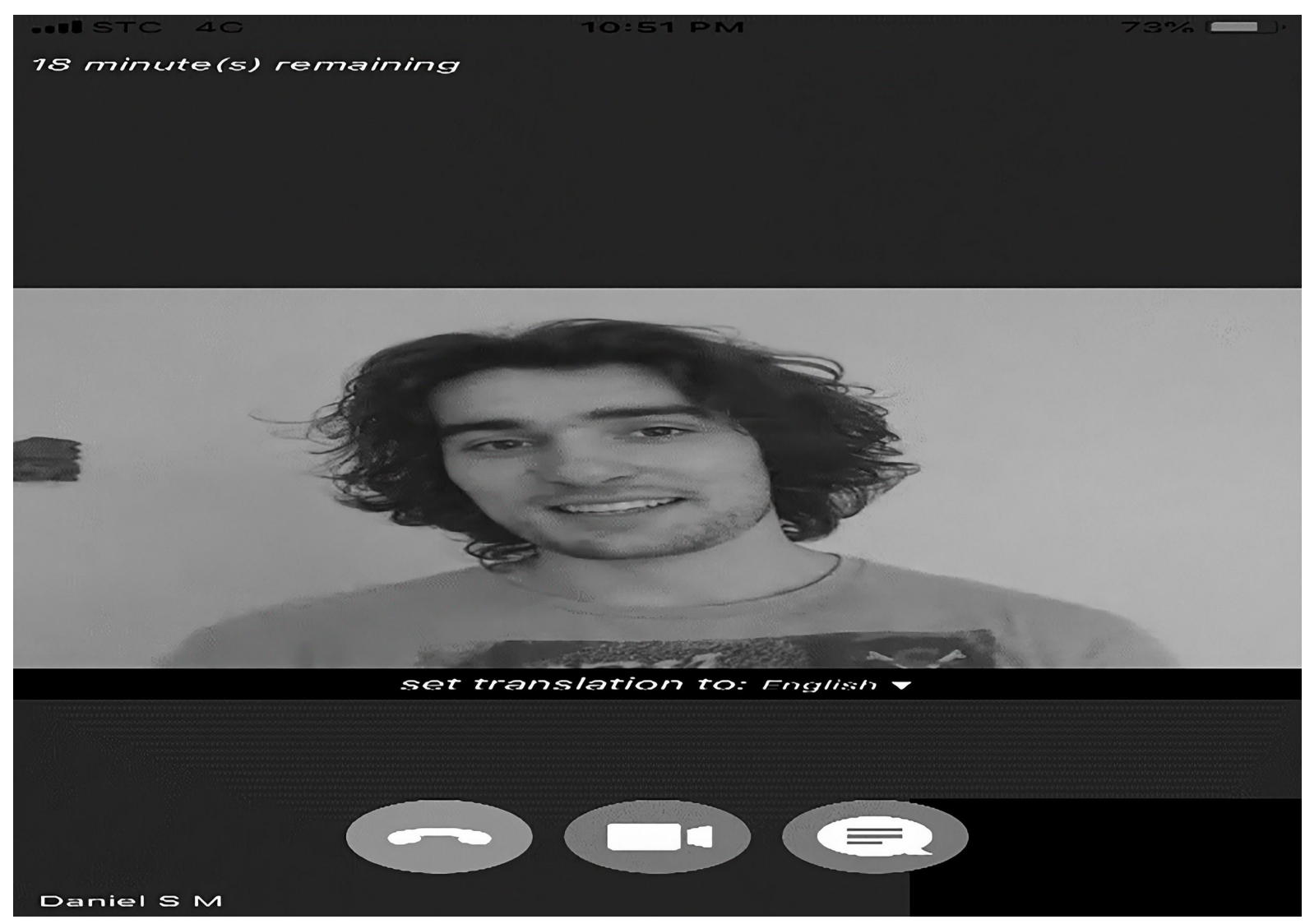

Figure 2. Screenshot from an Online Conversation with a Native English Speaker Conducted via Cambly

To ensure that all participants used their full weekly plan for the whole month, the researcher asked the participants to provide a screenshot of their audio call history within Cambly. The screenshot detailed the duration and time of each call as well as the identity of the tutor. Figure 3 shows a screenshot of one participant's call history during the first week.

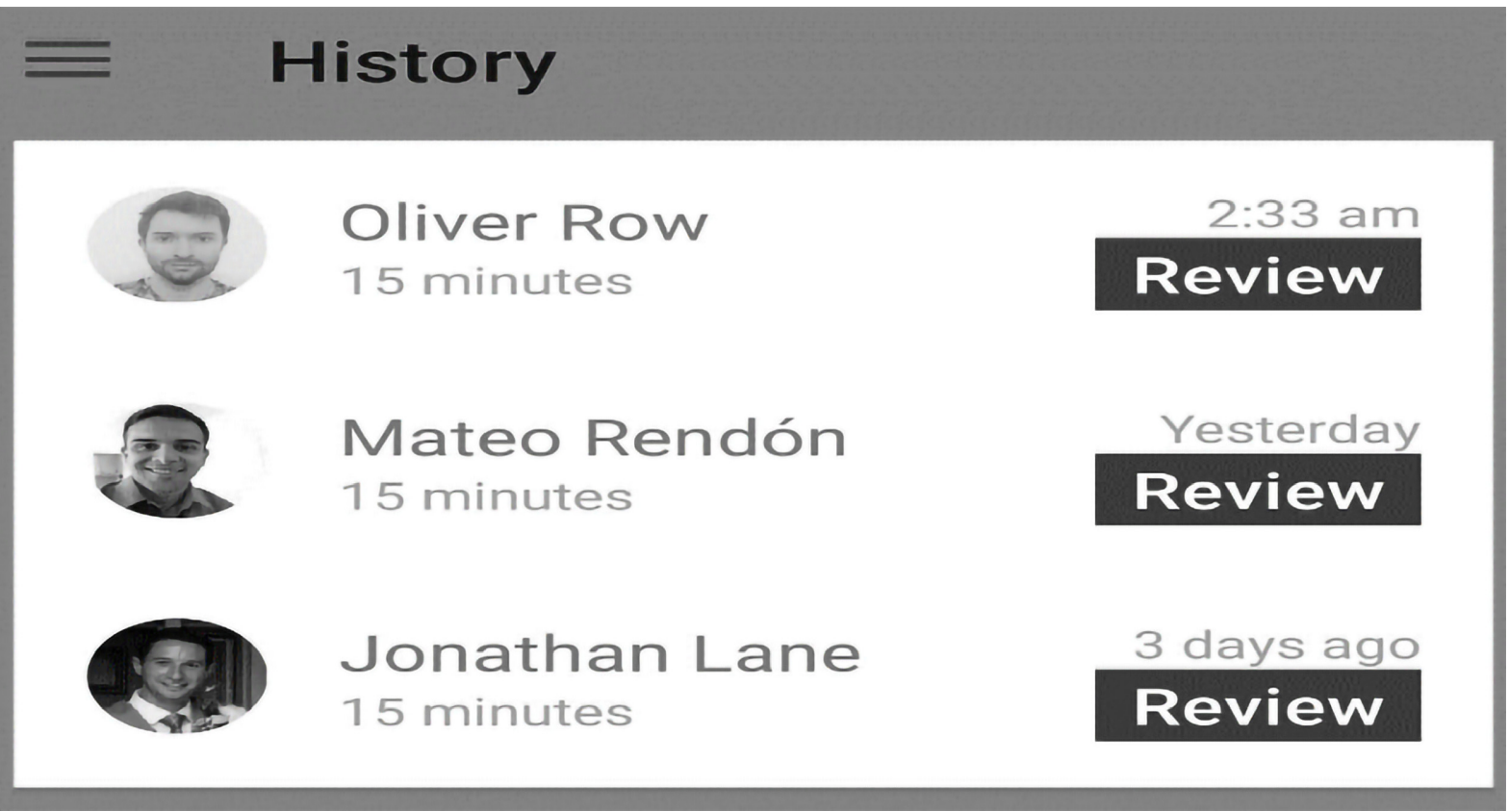

Figure 3. Screenshot of a Participant's Cambly History 
Due to the experimental design of the present study, the control group was required to share similarities with the experimental group but not to undergo the experimental intervention (Dornyei, 2007). This was necessary to ensure that any differences in the results were due to the experiment itself (Creswell, 2014). Additionally, this study required the involvement of a control group to make use of their results by comparing them with those of the experimental group. Therefore, the participants in the control group were only involved in the first and third phases of the study.

\subsubsection{The Third Phase}

The third phase marked the end of the experiment. In the week after the fourth and final week of the second phase, the researcher conducted the post-test for both the control and experimental groups over a 2-day period. Subsequently, the researcher randomly selected five participants from the experimental group to be interviewed. Finally, the researcher forwarded the participants' post-test recordings to the same Cambly evaluator who evaluated their pre-test recordings. The participants' interviews were also transcribed and then translated into English for further analysis.

\section{Results}

\subsection{The Impact of Using Cambly on the Participants' Speaking Proficiency}

Before evaluating and comparing the participants' mean pre- and post-test scores, the researcher generated descriptive statistics concerning the two groups using SPSS version 22 software. Table 1 shows that the experimental group had a mean score of 17.13 for the pre-test, while the control group had a mean score of 16.69. This indicates that the experimental and control groups were similar in terms of their mean scores before the experiment took place.

Table 1. Statistics on the Study Groups

\begin{tabular}{cccccc}
\hline & Group & $\mathrm{N}$ & Mean & Std. Deviation & Std. Error Mean \\
\hline $\begin{array}{c}\text { Pre-test } \\
\text { scores }\end{array}$ & Experimental & 15 & 17.13 & 2.924 & .755 \\
& Control & 13 & 16.69 & 2.898 & .803 \\
\hline
\end{tabular}

\subsubsection{Statistical Differences Between the Groups' Mean Post-test Scores}

The experimental and control groups' mean post-test scores were analyzed and compared using an independent samples t-test in order to determine whether there were any statistically significant differences between them and, if so, whether those differences could be attributed to the use of Cambly. The results of the independent samples t-test, which are presented in Table 2, show that the P-value in this regard to be 0.833 . Because $\alpha=0.05$, a P-value of .833 is not considered to be statistically significant. As a result, the first hypothesis, which suggested that there would be a significant difference between the mean post-test scores of the control and experimental groups, cannot be confirmed.

Table 2. Independent Samples Test Results

Levene's test for equality of variances

t-test for equality of means

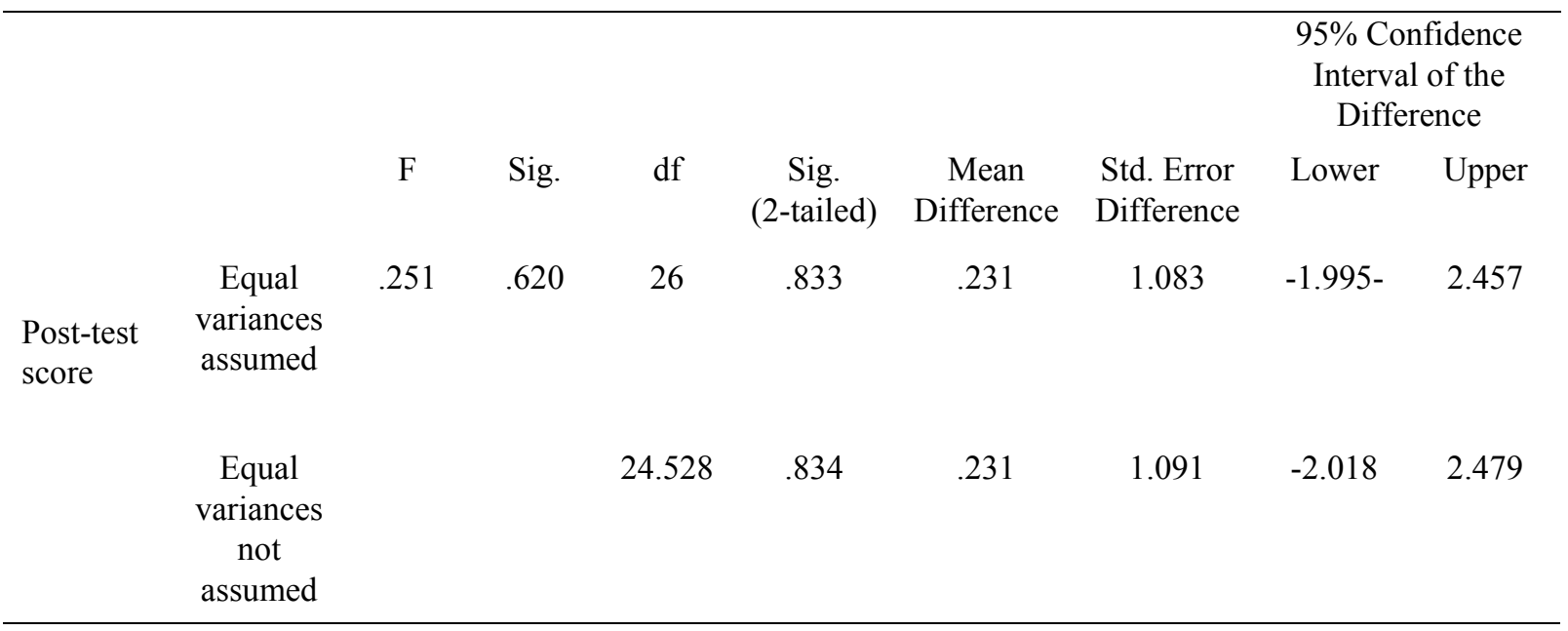




\subsubsection{Statistical Differences Between the Experimental Group's Mean Pre- and Post-test Scores}

The experimental group's pre- and post-test scores were analyzed and compared using a paired samples t-test to determine whether there was a statistically significant difference between them that could be attributed to the use of Cambly. The results of the paired samples t-test, which are presented in Table 3, show that the P-value in this regard is 0.078 , which is $>\alpha=0.05$. Consequently, the second hypothesis, which suggested that there would be a significant difference between the mean pre- and post-test scores of the experimental group, also cannot be confirmed.

Table 3. Paired Samples Test Results

\begin{tabular}{|c|c|c|c|c|c|c|c|c|c|}
\hline \multicolumn{10}{|c|}{ Paired Differences } \\
\hline & & \multicolumn{8}{|c|}{$\begin{array}{l}95 \% \text { Confidence } \\
\text { Interval of the } \\
\text { Difference }\end{array}$} \\
\hline & & Mean & $\begin{array}{c}\text { Std. } \\
\text { Deviation }\end{array}$ & $\begin{array}{l}\text { Std. } \\
\text { Error } \\
\text { Mean }\end{array}$ & Lower & Upper & $\mathrm{t}$ & df & $\begin{array}{l}\text { Sig. } \\
\text { (2-taile } \\
\text { d) }\end{array}$ \\
\hline Pair 1 & $\begin{array}{l}\text { Pre-test } \\
\text { score - } \\
\text { Post-test } \\
\text { score }\end{array}$ & $-.867-$ & 1.767 & .456 & $-1.845-$ & .112 & -1.899 & 14 & .078 \\
\hline
\end{tabular}

However, it must be recognized that a P-value of 0.078 is highly suggestive because it is very close to a value of 0.05 , which indicates that it would prove beneficial in the present case to examine the experimental group's preand post-test scores to determine whether they have improved or not. In fact, the mean pre-test score of 17.13 and the mean post-test score of 18, as presented in Figure 4, suggests there was a difference, albeit only a slight one, between the mean scores of the experimental group before and after the participants used Cambly.

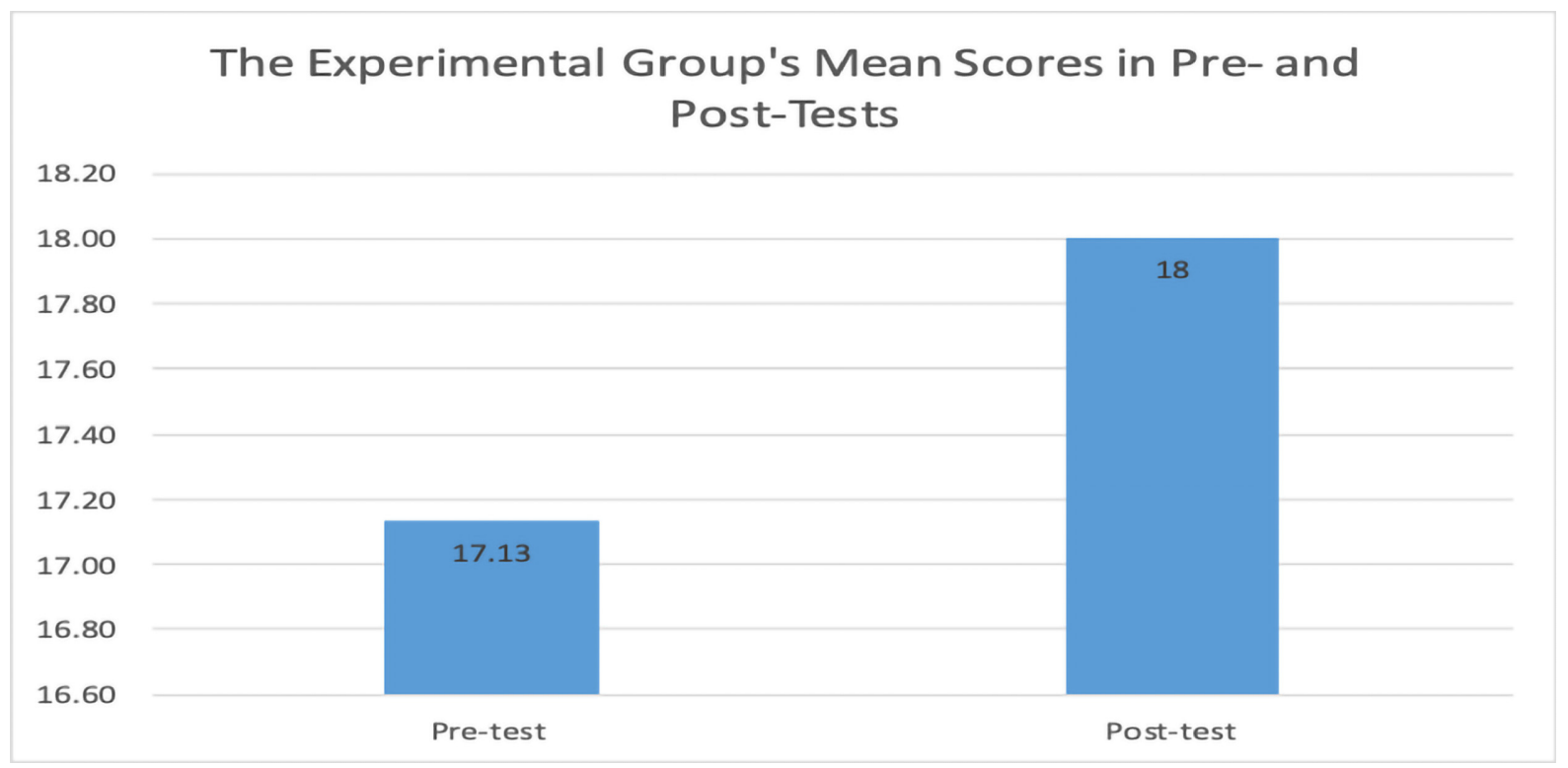

Figure 4. Mean Scores of the Experimental Group for the Pre- and Post-Tests

\subsection{Participants' Perceptions of Cambly}

The analysis of the participants' responses to the interview questions revealed that they exhibited positive attitudes toward the use of CMC tools to learn and practice English speaking. The participants believed that the experiment had helped them improve their L2 speaking proficiency. Additionally, they reported that the use of Cambly had a positive influence on their level of fluency because the time limit associated with Cambly calls caused them to speak quickly in an effort to communicate their ideas. Cambly also provided a native speaker model for the participants, meaning they could compare their language to the native speaker's language and then 
engage in self-correction. For instance, Participant $\mathrm{C}$ reported she now felt more comfortable speaking in English because the use of Cambly had prompted her to notice her mistakes and correct them.

The participants did not perceive Cambly to only be of relevance to the learning of L2 speaking. Indeed, the frequent opportunities to practice English Cambly offered also had a positive influence on the participants' motivation and anxiety levels. As Participant C commented, "Before using Cambly, I used to feel nervous when I wanted to speak in English, but using Cambly has decreased my anxiety and made me more comfortable." Cambly was perceived by the participants to be an enjoyable environment that provided a valuable and fun means of learning. Moreover, the participants revealed that the use of Cambly led them to build social relationships with the Cambly tutors and increase their cultural awareness. In this regard, Participant E commented, "Cambly allows you to get to know people from different cultures and to recognize perspectives and attitudes that are totally different from your own." Due to the perceived advantages Cambly offered, participants expressed their desire to continue using it as a learning resource.

\section{Discussion}

By investigating the use of a CMC tool, namely Cambly, the researcher attempted to provide a solution to the recognized problem of learners' weak speaking proficiency in EFL contexts (Alharbi, 2015; Nowrozi, 2011; Yen et al., 2015). The statistical analysis revealed that the participants' improvements in terms of their speaking proficiency after using Cambly were limited. This finding supported the findings of other prior studies (Castañeda, 2019; Grimshaw \& Cardoso, 2018). However, the qualitative analysis of the participants' interviews revealed that Cambly provided other advantages than simply improving their speaking proficiency. This contradiction between the quantitative and qualitative findings suggests that Cambly was a beneficial tool in relation to learning L2 speaking, although its positive impact was not statistically significant due to several limitations that were outside the control of the researcher.

The high cost of a Cambly subscription led to limitations in terms of both the duration of the study and the sample size. A total of 3 hours of engagement in audio calls with native speakers was really a very short intervention. This view was supported by Participant D, who commented, "I felt that I had improved, but not as much as I expected to. . . . The 15-minute period was not enough to improve my speaking proficiency." Although the duration of the experiment was not sufficient, some minutes were also wasted at the beginning of every call by the tutors, who always start by asking the users to talk about themselves, which prevented them from engaging in a diverse range of topics. Participant A referenced this problem when stating, "the tutors kept asking me to talk about myself during every call, which was boring."

The period in which the experiment was conducted was characterized by exams and deadlines. Thus, the mental and psychological pressure on the students might have hampered their improvement. Due to exam-related pressure, two participants each sacrificed 30 minutes of their Cambly time, while one participant sacrificed a full hour. Additionally, two participants each lost 30 minutes of their Cambly time due to technical issues. An extensive analysis of those five participants' pre- and post-test scores revealed that the lost time negatively impacted the results, as these participants achieved either the same or a lower score than their score for the pre-test. Moreover, the tutors were not following a general rule in terms of error correction. The participants who were satisfied with the experiment mentioned that the tutors corrected their errors, whereas the participants who were less satisfied commented that the tutors did not focus on their errors. For instance, Participant D stated, "Sometimes I felt that I had made a mistake, but they did not correct me. . . If they had corrected me, I would know my weaknesses and so be able to improve on them." Conversely, Participant B commented, "the tutors kept correcting my grammatical mistakes, which helped me to improve my grammar."

The qualitative findings of this study can be analyzed in light of Swain's (1985) and Krashen's (1982) theories. Participant E mentioned that practicing speaking using Cambly helped her regain a set of vocabulary had she lost through lack of use, which indicates that language production is an effective means of improving language proficiency. Furthermore, Participant D stated, "when a tutor pronounces a new word, I memorize it." This supports Krashen's (1982) view that listening to a language output that is slightly above the learner's current level represents a valuable means of improving that learner's language proficiency. The qualitative findings also supported Vygotsky's (1978) theory; Participant B noticed that after using Cambly she felt able to talk freely without mentally preparing what she wanted to say in advance. It can be inferred that when Participant B practiced new language structures that were not part of her initial language proficiency with the assistance of a native English speaker, she acquired those structures and thus enhanced her language abilities. 


\section{Conclusion}

The present study sought to investigate the impact of using Cambly on the speaking proficiency of EFL university students. Three major findings were discovered via the process of data analysis. First, the use of Cambly had a positive influence on the speaking proficiency of the participants in the experimental group, although this influence was not significantly noticeable when compared with the control group or even with the experimental group's pre-test scores. Second, the participants exhibited positive attitudes toward the use of a CMC tool, in this case Cambly, to practice L2 speaking. Third, the participants argued that the use of Cambly offered a number of advantages, including being an enjoyable tool for learning English speaking in a nonthreatening environment, having a positive influence on both motivation and anxiety, offering additional opportunities to practice English speaking, providing a native speaker model that prompted self-correction, building social relationships, and increasing cultural awareness.

Financial limitations influenced the results of the present study, so a more well-funded studying involving a larger sample and a longer duration is needed to support and explain the results of this study. Additionally, further research concerning Cambly that involves two groups, one under exam pressure and the other not, would help determine whether exam pressure and the resultant lack of focus could interfere with language development Finally, another study involving two groups using Cambly, one of which has their errors corrected by the tutors and one that does not, is needed to measure the impact of error correction on the increase in proficiency stemming from the use of $\mathrm{CMC}$ tools.

\section{Acknowledgements}

This paper is based on the author's master's thesis in linguistics. The author wishes to acknowledge the support provided by a number of professors at Al-Imam Mohammed Bin Saud Islamic University, including Dr. Ali Alrajhi, who supervised the author's thesis; Prof. Abdelhadi Tamim and Dr. Zuhair Zaghlool, who examined the author's thesis; and Dr. Manar Almanea, who was the participants' instructor. The author also wishes to express thanks to Alex Rubbo for his help in evaluating the study results as well as to the participants for taking part in this research.

\section{References}

Alfulaih, W. (2017). The impact of using games on developing Saudi female EFL students' speaking skill (Unpublished master's thesis). Al-Imam Mohammed Ibn Saud Islamic University, Riyadh, Saudi Arabia.

Alghammas, A. (2020). Web-based synchronous speaking platforms: Students' attitudes and practices. International Journal of English Linguistics, 10(3), 21-31. https://doi.org/10.5539/ijel.v10n3p21

Alharbi, H. A. (2015). Improving students' English speaking proficiency in Saudi public schools. International Journal of Instruction, 8(1), 105-116. https://doi.org/10.12973/iji.2015.818a

Alonayzan, A. (2015). The effect of using video blogs on the speaking performance among EFL university students (Unpublished master's thesis). Al-Imam Mohammed Ibn Saud Islamic University, Riyadh, Saudi Arabia.

Beatty, K. (2010). Teaching and researching computer-assisted language learning. London: Routledge.

Buckingham, L., \& Alpaslan, R. (2017). Promoting speaking proficiency and willingness to communicate in Turkish young learners of English through asynchronous computer-mediated practice. System, 65, 25-37. https://doi.org/10.1016/j.system.2016.12.016

Bygate, M. (2010). Speaking. Oxford: Oxford University Press.

Castañeda, D. A. (2019). Improving conversational interactions with task- based activities in a Spanish as a second $\begin{array}{lllll}\text { language class. Computer Assisted } & \text { Language }\end{array}$ https://doi.org/10.1080/09588221.2019.1666149

Creswell, J. (2014). Research design: Qualitative, quantitative, and mixed method approaches. Thousand Oaks, CA: Sage Publications.

Dornyei, Z. (2007). Research methods in applied linguistics. Oxford: Oxford University Press.

Dugartsyrenova, V. A., \& Sardegna, V. G. (2017). Developing oral proficiency with VoiceThread: Learners ' strategic uses and views. ReCALL, 29(1), 59-79. https://doi.org/10.1017/S0958344016000161

Grimshaw, J., \& Cardoso, W. (2018). Activate space rats! Fluency development in a mobile game-assisted environment. Language Learning \& Technology, 22(3), 159-175. https://doi.org/10125/44662

Guarda, M. (2012). Computer-Mediated-Communication and Foreign Language Education. Journal of e-Learning and Knowledge Society, 8(3), 15-27. Italian e-Learning Association. Retrieved 
from https://www.learntechlib.org/p/43275/

Herring S. (1996), Introduction, in: Herring S. (ed.), Computer-mediated communication: Linguistic, social and cross-cultural perspectives (pp. 1-10). Amsterdam, John Benjamins.

Hung, S.-T. A., \& Huang, H.-T. D. (2015). Video blogging and English presentation performance: A pilot study. Psychological Reports, 117(2), 614-630. https://doi.org/10.2466/11.PR0.117c20z6

Hymes, D. (1972). On communicative competence. In J.B. Pride \& J.Holmes (Eds.). Sociolinguistics. Harmondsworth, England:Penguin Books.

Ko, C. (2012). Can synchronous computer-mediated communication (CMC) help beginning-level foreign language learners speak? Computer Assisted Language Learning, 25(3), 217-236. https://doi.org/10.1080/09588221.2011.649483

Krashen, S. D. (1982). Principles and practice in second language acquisition. Oxford: Pergamon Press.

Lin, C., \& Hwang, G. (2018). A Learning Analytics Approach to Investigating Factors Affecting EFL Students' Oral Performance in a Flipped Classroom. Journal of Educational Technology \& Society, 21(2), 205-219. Retrieved from www.jstor.org/stable/26388398

Liu, T. Y., \& Chu, Y. L. (2010). Using ubiquitous games in an English listening and speaking course: Impact on learning outcomes and motivation. Computers and Education, 55(2), 630-643. https://doi.org/10.1016/j.compedu.2010.02.023

Long, M. (1983). Native speaker/nonnative speaker conversation in the second language classroom. In M. Clarke \& J. Handscombe (Eds), On TESOL82: Pacific perspectives on language learning and teaching (pp. 207-225). Washington, DC: TESOL.

Mehr, H., Zoghi, M., \& Assadi, N. (2013). Effects of synchronous computer-mediated communication and face-to-face interaction on speaking skill development of Iranian EFL learners. International Journal of Applied Linguistics \& English Literature, 2(5), 36-41. https://doi.org/10.7575/aiac.ijalel.v.2n.5p.36

Nowrozi, V. (2011). The rationale for using computer mediated communication to develop communicative \& linguistics competence in learners. English Language Teaching, 4(3), 200-206. https://doi.org/10.5539/elt.v4n3p200

Sun, Y.-C. (2012). Examining the effectiveness of extensive speaking practice via voice blogs in a foreign language learning context. CALICO Journal, 29(3), 494-506. https://doi.org/10.11139/cj.29.3.494-506

Swain, M. (1985). Communicative competence: Some roles of comprehensible input and comprehensible output in its development. In S. M. Gass \& C. G. Madden (Eds.), Input in second language acquisition (pp. 235-252). Cambridge, MA: Newbury House.

Vygotsky, L. (1978). Mind in society: The development of higher mental processes. Cambridge, MA: Harvard University Press.

Walliman, N. (2011). Research methods: The basics. London, UK: Routledge.

Wang, A. Y., \& Chang, W. (2011). Developing intercultural awareness and language speaking proficiency for foreign language learners through cross - cultural voicemail exchange. International Journal of Computer-Assisted Language Learning and Teaching, 1(4), 17-32. https://doi.org/10.4018/ijcallt.2011100102

Warschauer, M. (1996). Comparing face-to-face and electronic discussion in the second language classroom. CALICO Journal, 13(2), 7-26.

Wu, W. C. V., Hsieh, J., \& Yang, J. (2017). Creating an online learning community in a flipped classroom to enhance EFL learners' oral proficiency. Educational Technology \& Society, 20(2), 142-157.

Wu, W. V., Marek, M., \& Chen, N. (2013). Assessing cultural awareness and linguistic competency of EFL learners in a CMC-based active learning context. System, 41(3), 515-528. https://doi.org/10.1016/j.system.2013.05.004

Yeh, H., \& Lai, W. (2019). Speaking progress and meaning negotiation processes in synchronous online tutoring. System, 81, 179-191. https://doi.org/10.1016/j.system.2019.01.001

Yen, Y. C., Hou, H. T., \& Chang, K. E. (2015). Applying role-playing strategy to enhance learners' writing and speaking skills in EFL courses using Facebook and Skype as learning tools: a case study in Taiwan. Computer Assisted Language Learning, 28(5), 383-406. https://doi.org/10.1080/09588221.2013.839568 


\section{Appendix A}

\section{The Participants' Pre- and Post-Speaking Proficiency Test}

The participant will answer the following questions, one minute for each question. The participant will have one-minute preparation before each question.

Part I: Answer only ONE of the following:

1. What do you like to do in your free time?

2. Why are you studying English? Do you like it?

3. What is your least favorite subject in school? Why?

4. Can you briefly describe the plot of the last movie you saw? Did you enjoy watching it?

5. Describe a dream you had once. Why did you choose this dream in particular?

6. Name a place you have never been but would like to visit.

7. What do you think will be doing 10 years from now?

Part II: Choose one picture and talk about it.
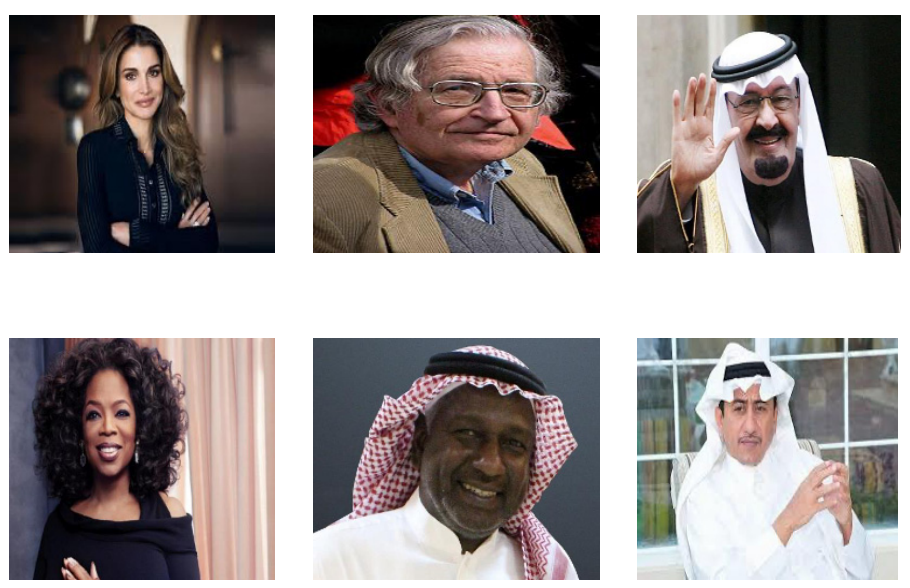

The participant will answer the following questions, one minute for each question. The participant will have one-minute preparation before each question.

Part I Answer only ONE of the following:

1. How would your best friend describe you? How would you describe her?

2. What is your favorite holiday? Why?

3. Is it easy for you to lend your things to others? If not, why not?

4. Would you interfere if there was a disagreement between your friends? If so, how would you settle the disagreement?

5. Would you adopt a stray dog or cat? Why?

6. Describe a special photograph in your home. Why is it special?

7. What is your happiest childhood memory? 
Part II Choose one picture and talk about it.
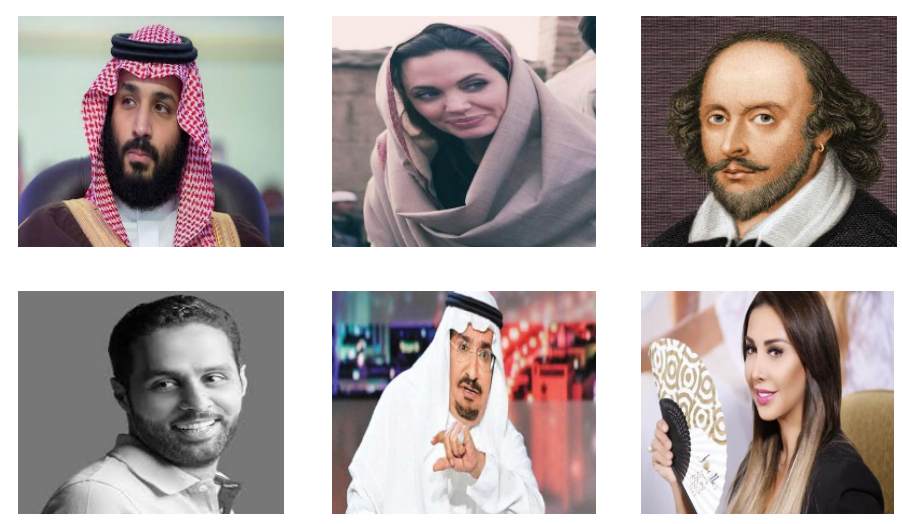

\section{Appendix B}

\section{The Rubric}

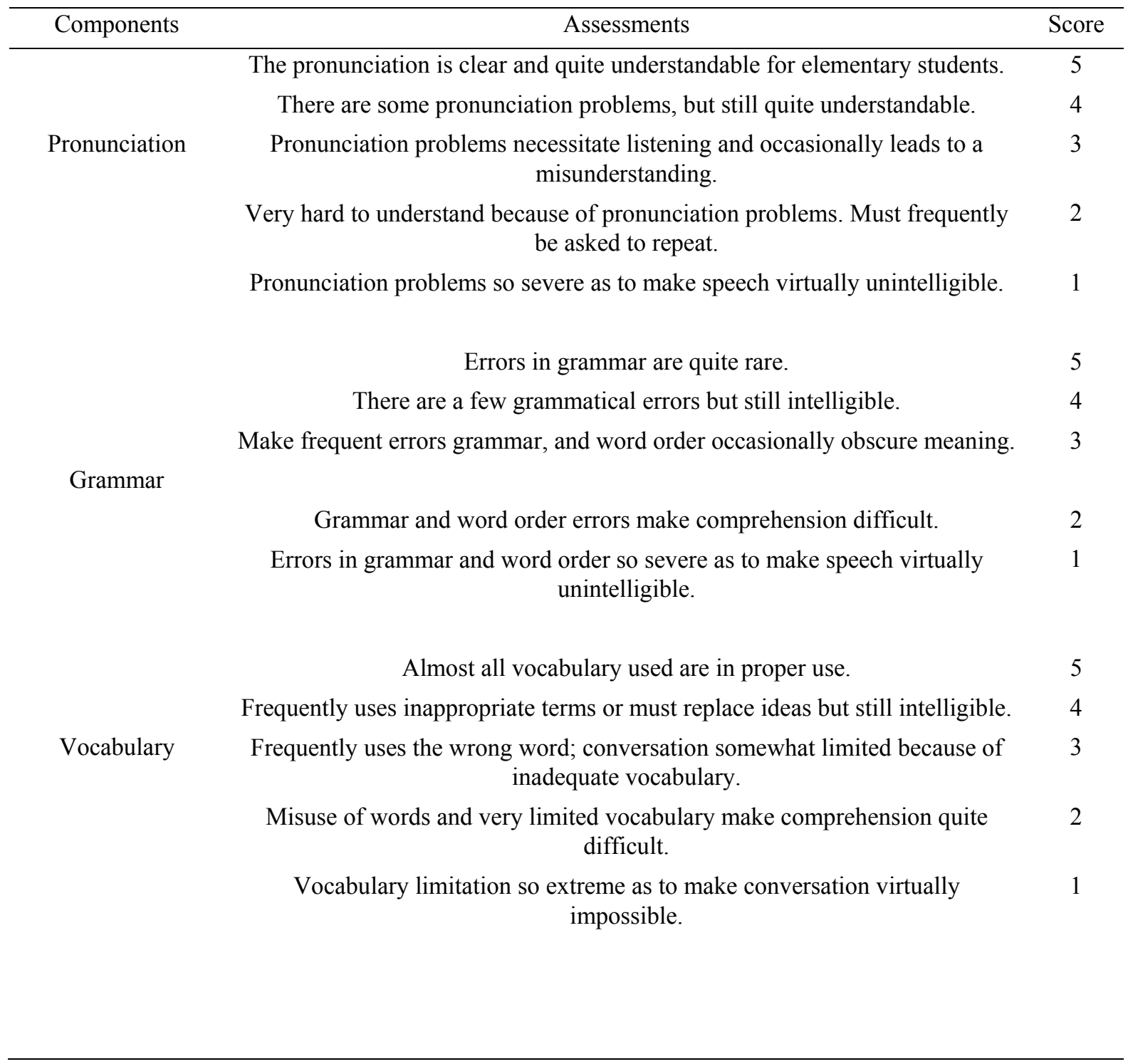


Able to use the language fluently, rare skips, and the speed of speech is at the

5

normal rate.

Speed of speech seems to be slightly affected by language problems. 4

Fluency

Speed and fluency are rather strongly affected by language problems.

3

Usually hesitant; often forced into silence by language limitations.

Speech is so halting and fragmentary as to make conversation virtually impossible.

Understands most of what is said at average speed.

5

Understands what is said at average speed, but occasional repetition may be 4 necessary.

Comprehension
3

Has great difficulty following what is said. Can comprehend only "social 2 conversation" spoken slowly and with frequent repetition.

Cannot be said to understand even simple conversational English.

\section{Appendix C}

\section{The Participants' Interview}

Q1: Do you feel that your L2 speaking proficiency has improved as a result of using Cambly? How?

Q2: Which parts in your speaking proficiency (pronunciation, fluency, grammar, vocabulary) have improved the most after using Cambly? Why?

Q3: Do you think that this experiment makes you more active in terms of oral class interaction? How?

Q4: Do you think that this experiment decreases your language anxiety and increases your motivation when speaking in English? Why? Why not?

Q5: What is the thing that you preferred the most in practicing speaking with Cambly? Why?

Q6: What are the difficulties that encountered you while practicing L2 speaking with Cambly?

Q7: Describe your overall experience in practicing speaking with Cambly.

Q8: Would you continue using Cambly in the future? Why? Why not?

\section{Copyrights}

Copyright for this article is retained by the author(s), with first publication rights granted to the journal.

This is an open-access article distributed under the terms and conditions of the Creative Commons Attribution license (http://creativecommons.org/licenses/by/4.0/). 